\title{
The effects of riboflavin on ischemia/reperfusion induced renal injury: Role on caspase- 3 expression
}

\author{
Betül AYAZ ADAKUL 1 (D) , Büşra ERTAŞ 1 (D) , Zatiye Ayça ÇEVÍKELLI 2 (D) , Dilek ÖZBEYLI ${ }^{3}$ (D),

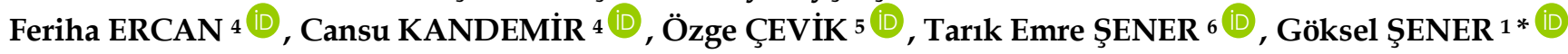

1 Department of Pharmacology, Faculty of Pharmacy, Marmara University, Haydarpaşa 34668 İstanbul, Turkey.

2 Department of Pharmacology, Faculty of Pharmacy, Trakya University, 22030 Edirne, Turkey.

3 Department of Medical Pathological Techniques, Vocational School of Health Services, Marmara University, İstanbul, Turkey.

4 Department of Histology \& Embryology, School of Medicine, Marmara University, Maltepe 34854 Istanbul, Turkey.

5 Department of Biochemistry, School of Medicine, Adnan Menderes University, 09010 Aydin, Turkey.

6 Department of Urology, School of Medicine, Marmara University, Maltepe 34854 Istanbul, Turkey.

* Corresponding Author. E-mail: gsener@marmara.edu.tr (G.Ş.); Tel. +90-216-414-29-62.

Received: 17 December 2018 / Revised: 23 January 2019 / Accepted: 25 January 2019

\begin{abstract}
Reactive oxygen metabolites play important roles in ischemia/reperfusion (I/R) injury in several organ systems. Riboflavin has been shown to exert antioxidant and/or anti-inflammatory activities in several experimental models. The aim of this study was to investigate the role of riboflavin against I/R injury in the rat kidney. Wistar albino rats 200-300 g weighing were divided into 3 groups. One week after unilateral nephrectomy, the IR procedure was applied to the rats. To induce I/R injury renal pedicle was clamped for 45 minutes and then rats were allowed reperfusion for 6 hours. Riboflavin $(25 \mathrm{mg} / \mathrm{kg}$, orally) or vehicle was administered for one week as pretreatment. After decapitation, kidney tissue samples were taken for the evaluation of malondialdehyde (MDA), an end product of lipid peroxidation; glutathione (GSH), a key antioxidant; and 8-hydroxydeoxyguanosine (8-OHdG), a specific marker of oxidative DNA damage. Furthermore, myeloperoxidase (MPO) and caspase-3 activities were also examined together with histological analysis. Ischemia/reperfusion induced significant increases in MDA and 8-OHdG levels and MPO and caspase- 3 activities, and decrese in GSH levels. In the riboflavin treatment these indices were found to be reversed back to control levels. The present data demonstrated that riboflavin, through its antioxidant effect, attenuates I/R induced acute renal injury in rats.
\end{abstract}

KEYWORDS: Antioxidants; ischemia reperfusion; riboflavin; caspase.

\section{INTRODUCTION}

Acute renal failure is a clinical problem that develops rapidly in the short term of kidney dysfunctions caused by several factors including ischemia/reperfusion (I/R) injury. It is important because of encountered frequently and high risk of mortality [1]. Renal I/R injury is occured during kidney transplantation, partial nephrectomy, renal artery angioplasty, cardiopulmonary bypass surgery, sepsis and some urological operations owing to interruption of renal blood flow temporarily and then return, results in acute renal failure [2].

In case of renal ischemic condition, due to insufficient oxygen transmission to the tissues energy metabolism is impaired. Reoxygenation of ischemic tissue leads to more injury, contrary to expectations [3]. Following by the I/R injury, several reactive oxygen species such as superoxide radical, hydrogen peroxide and hydroxyl radical are released that are thought to exacerbate acute renal failure. Furthermore, these reactive molecules increasing microvascular permeability, cause interstitial edema, impaired vasoregulation and structural changes in renal tubules concomitantly [4]. In addition, I/R injury causes acute inflammatory response via activated neutrophils infiltration into the tissue. Active neutrophils thought to exacerbate the damage by the release of reactive oxygen species and cytotoxic proteins into the extracellular fluid [5].

Elimination of reactive oxygen species that are released following I/R injury is important to reduce damage. Agents called free radical scavengers namely antioxidants may contribute to protection of cells and

How to cite this article: Ayaz Adakul B, Ertaş B, Çevikelli ZA, Özbeyli D, Ercan F, Kandemir C, Çevik Ö, Şener TE, Şener G. The effects of riboflavin on ischemia/reperfusion induced renal injury: Role on caspase-3 expression. J Res Pharm. 2019; 23(3): 379-386. 
tissues against harmful effects of reactive oxygen species [6]. Riboflavin (vit B2) is a water-soluble essential vitamin and found in foods such as meat, milk and fish [7]. The most biologically active forms of riboflavin are flavin adenine dinucleotide (FAD) and flavin mononucleotide (FMN) which act as an electron carriers in redox reactions in oxygenated respiratory cells [8]. Riboflavin has been shown that through both antioxidant and anti inflammatory properties it reduces lipid peroxidation, leukocyte infiltration and cytokine production and thus considered to be protective against I/R injury in liver, brain, lung and heart tissues [9-12]. Based on these data, this study was designed to determine if riboflavin is protective against renal ischemia/reperfusion injury.

\section{RESULTS}

\subsection{Malondialdehyde (MDA) and glutathione (GSH) levels}

MDA levels of renal tissue were found to be higher in I/R group $(34.33 \pm 6.55 \mathrm{nmol} / \mathrm{g}, \mathrm{p}<0.05)$ than sham-operated control group $(23.63 \pm 3.86 \mathrm{nmol} / \mathrm{g})$. In the riboflavin treated group MDA levels $(24.75 \pm 8.7$ $\mathrm{nmol} / \mathrm{mg}, \mathrm{p}<0.05)$ significantly decreased when compared with I/R group. (Fig. 1A). On the other hand, I/R injury caused decreases in renal tissue GSH levels $(0.87 \pm 0.14 \mu \mathrm{mol} / \mathrm{g}, \mathrm{p}<0.01)$ compared to the shamoperated control group $(1.17 \pm 0.1 \mathrm{nmol} / \mathrm{mg})$. Riboflavin treatment of the I/R group increased GSH levels $(0.96 \pm 0.2 \mu \mathrm{mol} / \mathrm{g}, \mathrm{p}<0.05)$ when compared with the I/R group. (Fig. 1B)
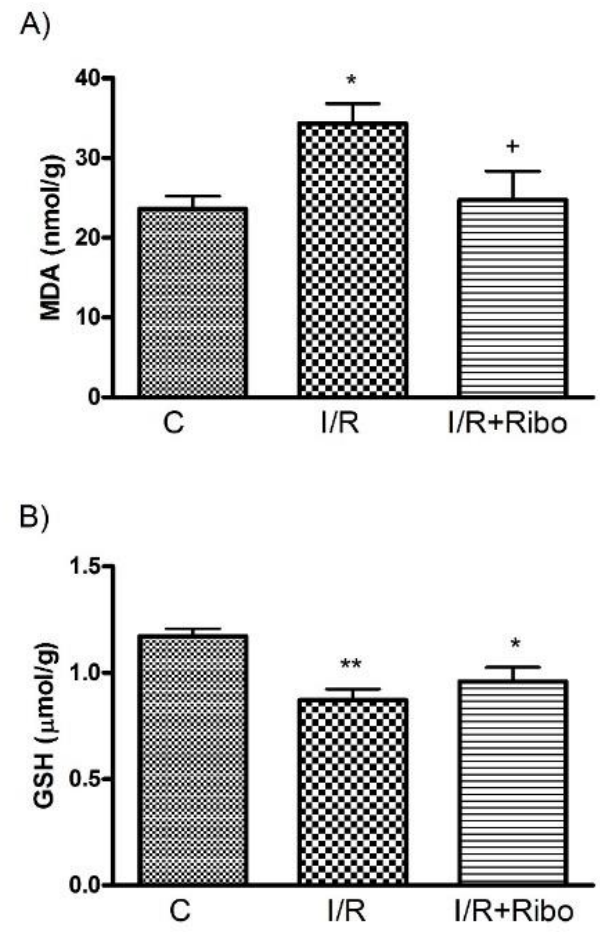

Figure 1. A) Malondialdehyde (MDA) and B) glutathione (GSH) levels in the kidney tissue of sham operated control $(C), I / R$ and I/ $R+$ Ribo groups $(n=8)$. ${ }^{*} p<0.05,{ }^{* *} p<0.01$ : vs sham operated control group. $+p<0.05$ : vs I/R group.

\subsection{Myeloperoxidase (MPO) activity and 8-hydroxydeoxyguanosine (8-OHdG) levels}

Myeloperoxidase activity which is a biomarker of neutrophil infiltration was found to be increased in the renal tissue of $\mathrm{I} / \mathrm{R}$ group $(13.10 \pm 3.55 \mathrm{U} / \mathrm{g}, \mathrm{p}<0.001)$ compared with sham-operated control group $(7.6 \pm$ $1.55 \mathrm{U} / \mathrm{g})$. Riboflavin treatment of the I/R group reduced this increment in the I/R+ Ribo group (10.05 \pm 1.03 $\mathrm{U} / \mathrm{g})$. (Figure 2) 


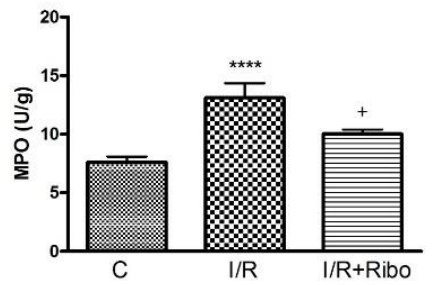

Figure 2. Myeloperoxidase (MPO) activity in the kidney tissue of sham operated control (C), I/R and $\mathrm{I} / \mathrm{R}+$ Ribo groups $(\mathrm{n}=8)$. ${ }^{* * *} \mathrm{p}<0.001$ : vs sham operated control group. $+\mathrm{p}<0.05$ : vs I/R group.

8-OHdG level which is an indicator of oxidative DNA damage was found to be inreased in I/R group $(\mathrm{p}<0.001)$ when compared with sham operated control goup. In riboflavin treated group $(\mathrm{I} / \mathrm{R}+\mathrm{Ribo})$ it was seen that 8-OHdG levels were significantly decreased $(\mathrm{p}<0.001)$ compared to I/R group (Fig.3).

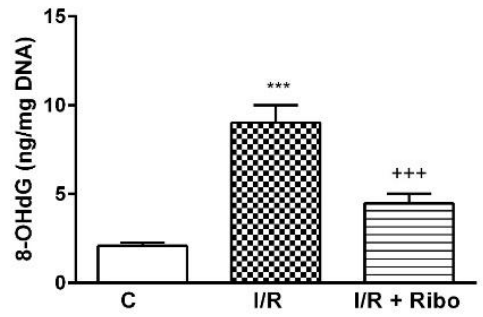

Figure 3. Oxidative DNA damage in kidney tissues of sham operated control (C), I/R and I/R+Ribo groups $(n=8) .{ }^{* * *} \mathrm{p}<0.001$ : vs saline-treated sham group, ${ }^{* *} \mathrm{p}<0.001$ : vs I/R group.

\subsection{Caspase-3 activity and caspase-3 protein expression}

As a result of I/R induced apoptosis, renal tissue caspase activity significantly increased $(p<0.001)$ compared to sham operated control group. When the riboflavin treated I/R group was examined, it was seen that the renal tissue caspase activity significantly decreased $(p<0.01)$ (Figure 4A).

Furthermore, when the Western blot data was evaluated the cleaved caspace-3 bands showed significant increases in the kidney tissues of I/R group $(p<0.001)$ while riboflavin treatment decreased cleaved caspase-3 ( $\mathrm{p}<0.001$; Fig. 4B). These data reflect the fact that riboflavin has protective effect on kidney tissues by controlling the I/R-induced apoptotic mechanism.
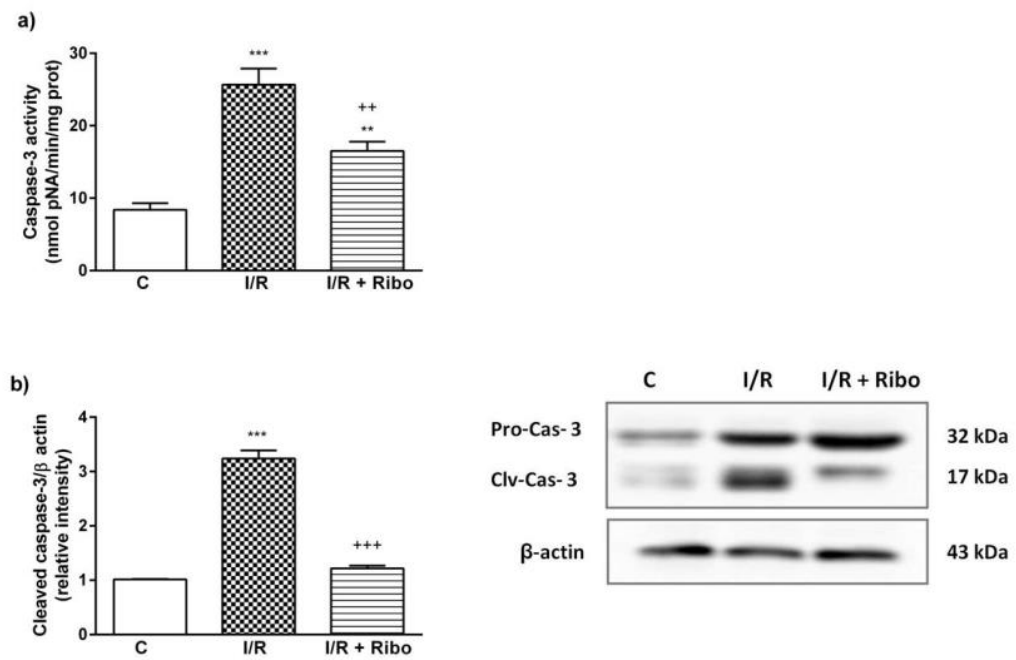

Figure 4. A) Caspase-3 activities and B) cleaved caspase-3 protein expression in kidney tissues determined by Western blotting in sham operated control (C), I/R and I/R+Ribo groups $(n=8) .{ }^{* *} p<0.01,{ }^{* * *} \mathrm{p}<0.001$ : vs saline-treated sham group, $++p<0.01,+++p<0.001$ : vs I/R group. 


\subsection{Histological results}

Light microscopical observation of kidney tissues in sham operated control rats (Fig. 5A) showed regular renal parenchyma with glomeruli and tubuli with PAS positive (+) staining. IR group (Fig. $5 \mathrm{~B})$ showed degenerated renal corpuscles with dilated Bowman space and cellular debris, atrophic glomeruli, degenerated tubular cells with decreased PAS + staining in apical surface, luminal debris and severe interstitial bleeding in renal parenchyma. I/R+Ribo group (Fig.5C) showed vascular congestion in glomeruli and renal parenchyma, moderate degeneration in tubular cells. PAS+ apical surface was present in regular tubuli in this group.
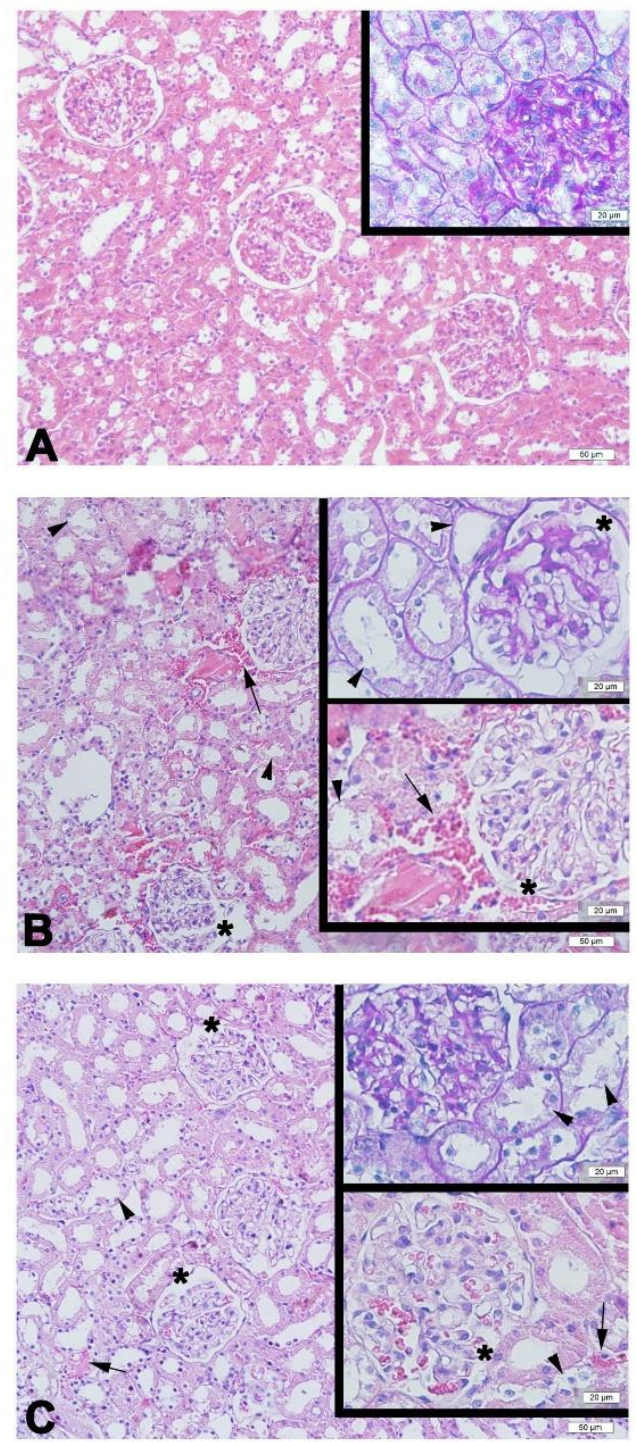

Figure 5. Representative light micrographs of renal tissues in experimental groups. A) Sham operated control group showed regular morphology of renal corpuscles and tubuli in kidney. B) IR group showed severe dilatation of Bowman space with cellular debris and congestion in glomeruli $\left({ }^{*}\right)$, degenerated tubular cells with luminal debris (arrow heads) and severe interstitial bleeding (arrow) in kidney parenchyma. C) IR+Ribo group showed vascular congestion in glomeruli $\left(^{*}\right)$ and renal parenchma, moderate tubular degeneration (arrowhead) and mild interstitial bleeding (arrow). PAS+ staining (arrowhead) was not seen in apical surface of degenerated tubules in experimental groups (B and C). H\&E staining, insets and above insets in B and C: PAS staining. 


\section{DISCUSSION}

The results of the current study demonstrate that temporary interruption of the renal blood supply and subsequent reperfusion led to structural damages in the kidney based on oxygen deprivation-induced cell injury through inflammatory response and production of reactive oxygen species. On the other hand, the results of the current study suggest that riboflavin treatment has protective effect on I/R induced damage in the kidney.

Lipid peroxidation is an autocatalytic mechanism leading to oxidative damage of cell membrane. Membrane associated polyunsaturated fatty-acids are lightly attached by $\mathrm{OH}$ - in a process that leads to peroxidation of lipids [13]. Malondialdehyde levels are indicative of lipid peroxidation and elevated levels of MDA, as shown in this study, demonstrated that IR causes damage to the membrane lipids. This observation is in agreement with previous studies that levels of lipid peroxides were increased above basal values [14, 15]. Our study indicated that riboflavin treatment reduces renal MDA levels through its antioxidative properties. It has been previously shown that riboflavin treatment decreased MDA levels in liver [16], brain [17] and lung [18] and thus protected against carbon tetrachloride-induced hepatotoxicity, stroke and lipopolysaccharideinduced lung injury respectively. Therefore, the reduction of MDA levels presented here probably contributed in great sense to the inhibition of I/R events in kidney tissues.

Oxidative stress-induced tissue damage can be avoided or reduced by intracellular antioxidants. Glutathione is known as the main endogenous component that provides protection against oxidative damage in the cellular system of defense by attaching various electrophilic radicals and metabolites [19]. Oxidative damage in the cell increases generation of oxygen radicals which deplete antioxidant stores. When GSH stores were depleted the cell becomes vulnerable and damage is inevitable. The results of the current study showed that depletion of tissue GSH, as seen in I/R group, allowed lipid peroxidation and renal tissue damage. On the other hand, riboflavin treatment preserved the GSH levels and lowered kidney oxidative stress in this study. The effect of riboflavin status on reduced glutathione content in tissues has been investigated in a limited number of studies. Decreased GSH levels have been reported to increase by riboflavin treatment in carbon tetrachloride-induced hepatotoxicity, stroke and lipopolysaccharide-induced lung injury models. [1618]. Our data are consistent with these previous studies. This effect may be due to the riboflavin acting as an electron carriers in redox reactions. Neutrophils are potential source of reactive oxygen species, besides, reactive oxygen species play a role in the infiltration of neutrophils into post ischemic tissue [20]. They are also considered to be effective in tissue damage that occurs in several inflammatory processes including reperfusion injury. Myeloperoxidase (MPO) is enyzme that plays an important role in production of oxidative agents by neutrophils [5]. In the present study MPO activity, as a marker of neutrophil infiltration, was increased by I/R injury while this increase was reduced by riboflavin treatment. In agreement with this result, Sanches et al. showed that I/R induced elevated neutrophil infiltration to damaged tissue was reduced by riboflavin [9]. All these results suggest that the riboflavin-induced amelioration of oxidative stress may also be directly related to the decrease in neutrophil recruitment into the organs.

DNA damage is induced by cellular metabolites such as ROS or exogenous agents and may be cause mutation, aging or death of cell. 8-OHdG, which is formed by the reaction of OH radical, the strongest reactive oxygen species, with guanine base, is known as an indicator of oxidative DNA damage [21]. Various studies have shown that oxidative stress increases the formation of 8 -OHdG [21, 22]. In this study, ischemia/reperfusion in kidney tissues increased oxidative DNA damage as assessed by increased 8-OHdG levels while this increase is reversed by riboflavin treatment.

Cell production and death are in equilibrium in achieving tissue homeostasis. Apoptosis is programmed cell death in providing this homeostasis. Caspases are the family of enzymes that are activated in the first stages of apoptosis, responsible for the catabolism of cytoskeletal proteins and nuclear proteins. It is known that oxidative stress and ROS may lead to apoptosis [22]. In recent studies, exposure of cell to oxidants has been shown to activate caspases which play role in apoptosis [23, 24]. Therefore, measurement of caspase activity is meaningful to observe oxidative stress induced apoptosis. The current study demonstrates that apoptosis triggered by renal I/ $R$ that observed by increased caspase activity is returned to normal course by riboflavin treatment. Furthermore, in agreement with these caspase activty data, I/R caused significant increase in active caspase- 3 protein expression while this increase was suppressed by riboflavin treatment.

\section{CONCLUSION}

Our results demonstrated that riboflavin treatment prevents the kidney tissue damage against I/R injury and this protective effects of riboflavin can be attributed to reduce neutrophil infiltration, to provide 
oxidant-antioxidant balance and thereby to prevent lipid peroxidation and DNA damage. In this case, riboflavin could be used as a potential therapeutic agent in I/R induced acute renal failure.

\section{MATERIALS AND METHODS}

\subsection{Animals and ethics}

Male Wistar Albino rats (200-250 g) were housed in an air-conditioned room with $12 \mathrm{~h}$ light and dark cycles, where the temperature $(22 \pm 2 \mathrm{C})$ and relative humidity $(65-70 \%)$ were kept constant. They were obtained from Marmara University (MU) Application and Research Center for Experimental Animals (DEHAMER). All experimental protocols were approved by the MU Animal Care and Use Committee (\#114.2016.mar). To induce anaesthesia rats were injected with intraperitoneally $100 \mathrm{mg} / \mathrm{kg}$ ketamine and $0.75 \mathrm{mg} / \mathrm{kg}$ chlorpromazine.

\subsection{Surgery and experimental protocol}

Rats were divided into three groups each consisting of eight animals: Sham operated control (sham), Ischemia reperfusion (I/R) and Riboflavin-treated I/R groups. Under anesthesia a right nephrectomy was performed and the left renal pedicle was occluded for $45 \mathrm{~min}$ to induce ischemia prior to reperfusion for $6 \mathrm{~h}$ [25]. Rats were treated with either saline (I/R group) or riboflavin $(25 \mathrm{mg} / \mathrm{kg}$, p.o.; I/R+Ribo) during 7 days before the surgery and at the beginning of reperfusion. The dose of riboflavin used in this study is based on previous studies where the antioxidant effects of riboflavin were observed [26]. Sham-operated control rats underwent laparotomy only, where the kidneys were manipulated without nephrectomy or occlusion.

The experiment took place in the setting of heating lamp and warm saline irrigation of abdominal cavity preoperatively to prevent hypothermia as well as fluid replacement. At the end of the reperfusion period rats were decapitated. Renal tissue samples were taken and stored at $-80^{\circ} \mathrm{C}$ for biochemical analyses, while tissues were also taken for morphological evaluation.

\subsection{Biochemical analysis}

\subsubsection{Chemicals}

Riboflavin, o-dianisidine, dithiobisnitrobenzoate (DTNB), hexadecyltrimethylammonium bromide (HETAB) were obtained from Sigma Chemical Co. (St Louis, MO, USA) and trichloroacetic acid, 2thiobarbituric acid, 5,5'-dithiobis (2-nitrobenzoic acid) from Merck (Darmstadt, Germany). All other chemicals were of the purest grade commercially available.

\subsubsection{Measurement of tissue MDA and GSH levels}

Tissue samples were homogenized in 10 volumes of ice-cold $10 \%$ trichloracetic acid and centrifuged at $3000 \mathrm{rpm}$ for $15 \mathrm{~min}$ at $4^{\circ} \mathrm{C}$. The MDA levels, an end product of lipid peroxidation were assayed by monitoring thiobarbituric acid reactive substance formation as described previously [27]. GSH was determined by a spectrophotometric method which is a modification of Ellman procedure [28].

\subsubsection{Measurement of tissue myeloperoxidase activity}

MPO activity was measured in tissues in a procedure similar to that documented by Hillegas et al [29]. After homogenization of the tissue samples with potassium phosphate buffer ( $\mathrm{PB}, \mathrm{pH}$. 6.0) and then centrifugation, obtained pellets obtained were suspended with hexadecyltrimethylammonium bromide (HETAB). Mixing of the supernatant with o-dianisidine and $\mathrm{H} 2 \mathrm{O} 2$ solution, MPO activity was calculated by a change in absorbance measured at $460 \mathrm{~nm}$ for 3 minutes on a spectrophotometer (Spectrophtometer, Beckman Coulter DU 73, Fullerton, California, US.).

\subsubsection{Measurement of tissue caspase-3 activity}

Caspase-3 activity assay was performed using the caspase-3 cellular activity assay kit (Calbiochem, San Diego, CA) according to the manufacturer's instructions. The DEVDpNA cleavage activity was calculated as $\mathrm{pmol} / \mathrm{min} / \mathrm{mg}$ protein. Protein concentration in tissue samples was determined using Bradford method [30].

\subsubsection{Western blot analysis for Caspase-3}

Caspase-3 protein expression was measured directly by Western blot using a monoclonal rat anticaspase-3 and cleaved caspase-3 (clv-cas3) antibodies. Samples were homogenized with cell lysis buffer and 
then centrifuged sample supernatant was collected for determining immunobloting assay. Samples resolved on $12 \%$ SDS-PAGE and transferred to nitrocellulose membrane. The membrane was blocked with $5 \%$ nonfat skimmed milk powder then washed with TBST and incubated overnight with primary antibody (1:500 monoclonal rat anti-caspase-3 sc-56055; anti-b-actin, sc-47778 from Santa Cruz Biotechnology, clv-casp3 9664 from Cell Signaling). The membrane was incubated with HRP conjugated secondary antibody for $2 \mathrm{~h}$. After the incubation, membrane was developed with chemiluminescence reagents (sc-2048, Santa Cruz Biotechnology L kit) and exposed to Fuji Super RX fi lm (47410, Tokyo, Japan). Protein bands were analyzed using "Image J Programme Optical Density Analysis Software" (NIH, USA). Signals were normalized with respect to $\beta$-actin.

\subsubsection{Tissue 8-hydroxy-2 '-deoxyguanosine levels measurement}

Commercial DNA extraction kit was used to extract the genomic DNA (Invitrogen, US). Measurement of tissue 8-hydroxy-2'-deoxyguanosine (8-OHdG) levels were performed using OxiSelect Oxidative DNA Damage ELISA kit according to the manufacturer instructions. (Cell Biolabs, US).

\subsection{Histological analysis}

For light microscopical examination kidney tissue samples were fixed with $10 \%$ neutral formalin, dehydrated in ascending alcohol series, cleared with toluene, and embedded in paraffine. Approximately $5 \mu \mathrm{m}$ thick kidney sections were stained with hematoxylin and eosin (H\&E) and periodic acid Schiff (PAS). Stained sections were evaluated with an Olympus BX51 photomicroscope (Tokyo, Japan) and photographed with Olympus DP72 digital camera (Tokyo, Japan).

\subsection{Statistical analysis}

Statistical analysis was performed using GraphPad Prism 6.0 (GraphPad Software, San Diego, CA, USA). Each group consisted of six animals. All data are expressed as the mean \pm SEM. Groups of data were compared with ANOVA followed by Turkey's multiple comparison tests. Statistical significance was accepted as $\mathrm{p}<0.05$.

Author contributions: Concept - B.A.A., B.E., G.Ş. ; Design - B.E., G.Ş., D.Ö., T.E.Ş.; Supervision - G.Ş., T.E.Ş.; Resource - B.A.A., B.E., G.Ş.; Materials - Z.A.Ç., B.E., Ö.Ç., F.E., C.K.; Data Collection and/or Processing - G.Ş., B.E.; Analysis and/or Interpretation - G.Ş., B.E., B.A.A..; Literature Search - G.Ş., B.E., T.E.Ş.; Writing - G.Ş., B.A.A., T.E.Ş..; Critical Reviews - G.Ş., T.E.Ş., B.A.A., B.E., D.Ö., Z.A.Ç., Ö.Ç., F.E., C.K.

Conflict of interest statement: The authors declare that they have no conflict of interest.

\section{REFERENCES}

[1] Eltzschig HK, Eckle T. Ischemia and reperfusion--from mechanism to translation. Nat Med. 2011; 17: 1391-401. [CrossRef]

[2] Şener G, Sehirli AO, Keyer-Uysal M, Arbak S, Ersoy Y, Yegen BC. The protective effect of melatonin on renal ischemia-reperfusion injury in the rat. J Pineal Res. 2002; 32: 120-6. [CrossRef]

[3] Parks DA, Bulkley GB, Granger DA, Hamilton SR, Mccord JM. Ischemic injury in the cat small intestine: Role of superoxide radicals. Gastroenterology. 1982; 82: 9-15.

[4] Sutton TA. Alteration of microvascular permeability in acute kidney injury. Microvasc Res. 2009; 77: 4-7. [CrossRef]

[5] Kettle AJ, Winterbourn CC. Myeloperoxidase: A key regulator of neutrophil oxidant production. Redox Rep. 1997; 3: 3-15. [CrossRef]

[6] Singh D, Kaur R, Chander V, Chopra K. Antioxidants in the prevention of renal disease. J Med Food. 2006; 9: 443-50. [CrossRef]

[7] Powers HJ. Riboflavin (vitamin B-2) and health. Am J Clin Nutr. 2003; 77: 1352-1360. [CrossRef]

[8] Ashoori M, Saedisomeolia A. Riboflavin (vitamin B2) and oxidative stress: A review. Br J Nutr. 2014; 111: 1985-1991. [CrossRef]

[9] Sanches SC, Ramalho LN, Mendes-Braz M, Terra VA, Cecchini R, Augusto MJ, Ramalho FS. Riboflavin (vitamin B-2) reduces hepatocellular injury following liver ischaemia and reperfusion in mice. Food Chem Toxicol. 2014; 67: 65-71. [CrossRef] 
[10] Betz AL, Ren XD, Ennis SR, Hultquist DE. Riboflavin reduces edema in focal cerebral ischemia. Acta Neurochir Suppl (Wien). 1994; 60: 314-317. [CrossRef]

[11] Seekamp A, Hultquist DE, Till GO. Protection by vitamin B2 against oxidant-mediated acute lung injury. Inflammation. 1999; 23: 449-460. [CrossRef]

[12] Kotegawa M, Sugiyama M, Haramaki N. Protective effects of riboflavin and its derivatives against ischemic reperfused damage of rat heart. Biochem Mol Biol Int. 1994; 34: 685-691.

[13] García JJ, Reiter RJ, Guerrero JM, Escames G, Yu BP, Oh CS, Muñoz-Hoyos A. Melatonin prevents changes in microsomal membrane fluidity during induced lipid peroxidation. FEBS Lett. 1997; 408: 297-300. [CrossRef]

[14] Sehirli AO, Sener G, Satıroglu H, Ayanoglu-Dulger G. Protective effect of N-acetylcysteine on the renal ischemia/reperfusion injury in the rat. J Nephrol. 2003; 16: 75-80.

[15] Aragno M, Cutrin JC, Mastrocola R, Perrelli MG, Restivo F, Poli G, Danni O, Boccuzzi G. Oxidative stress and kidney dysfunction due to ischemia/reperfusion in rat: attenuation by dehydroepiandrosterone. Kidney Int. 2003; 64: 836843. [CrossRef]

[16] Al-Harbi NO, Imam F, Nadeem A, Al-Harbi MM, Iqbal M, Ahmad SF. Carbon tetrachloride-induced hepatotoxicity in rat is reversed by treatment with riboflavin. Int Immunopharmacol. 2014; 21: 383-388. [CrossRef]

[17] Franca CF, Vianna LM. Effectiveness of B vitamins on the control of hypertension and stroke events of SHRSP rats. J Diet Suppl. 2010; 7: 71-77. [CrossRef]

[18] Al-Harbi NO, Imam F, Nadeem A, Al-Harbi MM, Korashy HM, Sayed-Ahmed MM, Hafez MM, Al-Shabanah OA, Nagi MN, Bahashwan S. Riboflavin attenuates lipopolysaccharide-induced lung injury in rats. Toxicol Mech Methods. 2015; 25: 417-423. [CrossRef]

[19] Szabo S, Nagy L, Plebani M. Glutathione, protein sulfhydryls and cysteine proteases in gastric mucosal injury and protection. Clin Chim Acta. 1992; 206: 95-105. [CrossRef]

[20] Zimmerman BJ, Grsham MB, Granger DN. Role of oxidants in ischemia/reperfusion induced granulocyte infiltration. Am J Physiol. 1990; 258: G185-190. [CrossRef]

[21] Karakoyun B, Ertaş B, Yüksel M, Akakın D, Çevik Ö, Şener G. Ameliorative effects of riboflavin on acetic acidinduced colonic injury in rats. Clin Exp Pharmacol Physiol. 2018; 45: 563-572. [CrossRef]

[22] Tekin G, İsbir S, Şener G, Çevik Ö, Çetinel Ş, Dericioğlu O, Arsan S, Çobanoğlu A. The preventive and curative effects of melatonin against abdominal aortic aneurysm in rats. J Vasc Surg. 2018; 67: 1546-1555. [CrossRef]

[23] Grunenfelder J, Miniati DN, Murata S, Falk V, Hoyt EG, Kown M, Koransky ML, Robbins RC. Upregulation of Bcl-2 through caspase-3 inhibition ameliorates ischemia/reperfusion injury in rat cardiac allografts. Circulation. 2001; 104: I202-206.

[24] Sener TE, Tavukcu HH, Atasoy BM, Cevik O, Kaya OT, Cetinel S, Dagli Degerli A, Tinay I, Simsek F, Akbal C, Butticè $\mathrm{S}$, Sener G. Resveratrol treatment may preserve the erectile function after radiotherapy by restoring antioxidant defence mechanisms, SIRT1 and NOS protein expressions. Int J Impot Res. 2018; 30: 179-188. [CrossRef]

[25] Sener G, Sehirli O, Velioglu Ogunc A, Cetinel S, Gedik N, Caner M, Sakarcan A, Yeğen BC. Montelukast protects against renal ischemia/reperfusion injury in rats. Pharmacol Res. 2006; 54: 65-71. [CrossRef]

[26] Yu Z, Morimoto K, Yu J, Bao W, Okita Y, Okada K. Endogenous superoxide dismutase activation by oral administration of riboflavin reduces abdominal aortic aneurysm formation in rats. J Vasc Surg. 2016; 64: 737-745. [CrossRef]

[27] Beuge JA, Aust SD. Microsomal lipid peroxidation. Meth Enzymol. 1978; 52: 302-311. [CrossRef]

[28] Beutler E. Glutathione in red blood cell metabolism. A Manuel of Biochemical Methods. Grune \& Stratton, New York, 1975; pp. 112-114.

[29] Hillegass LM, Griswold DE, Brickson B, Albrightson-Winslow C. Assessment of myeloperoxidase activity in whole rat kidney. J Pharmacol Methods. 1990; 24: 285-295. [CrossRef]

[30] Bradford MM. A rapid and sensitive method for the quantitation of microgram quantities of protein utilizing the principle of protein-dye binding. Anal Biochem. 1976; 72: 248-254. [CrossRef] 